\title{
Sektion 8
}

\section{Austausch und Konflikte II - 19. und 20. Jahrhundert}

\author{
Sektionsleiterin: Professor Dr. Dr. h.c. Gudrun Krämer (Freie Universität Berlin) \\ Referenten: $\quad$ Professor Dr. Lucette Valensi (EHESS Paris) \\ Professor Dr. Leila Fawaz (Tufts University) \\ Professor Dr. Dr. h.c. Martin Tamcke (Georg-August-Universität \\ Göttingen)
}

\section{Einführung}

Die Beiträge der Sektion „Austausch und Konflikte II“ führen uns zeitlich in das „lange 19. Jahrhundert“, das erst mit dem Ersten Weltkrieg sein Ende fand, und geographisch in den erweiterten Mittelmeerraum, der hier so weit gefasst wird, dass er auch den Iran umschließt. Zwei Historikerinnen sind in dieser Sektion versammelt und ein Theologe und Missionswissenschaftler; sie nähern sich dem Thema verständlicherweise auf unterschiedliche Art. Zwei Themen stehen im Mittelpunkt ihrer Überlegungen: zum einen das Verhältnis von Austausch und Konflikt im Miteinander unterschiedlicher ethnischer und religiöser Gruppen in diesem Raum zu dieser Zeit, zum anderen der Stellenwert von Religion für den Charakter ihrer - um es so allgemein zu formulieren - Begegnungen, und zwar nicht nur der konfliktförmigen.

„Does religion always matter?" Ist Religion (wirklich) immer ein bestimmender Faktor dieser Begegnungen? Sowohl Lucette Valensi als auch Leila Fawazbeide herausragende Historikerinnen des Vorderen Orients in der Frühen Neuzeit und der Neuzeit, die eine mit Schwerpunkt Maghreb, die andere mit Schwerpunkt Fruchtbarer Halbmond - verneinen dies ausdrücklich. Die Thesen heutiger Islamisten, die den Islam für Fundament und Rahmen allen islamisch/muslimischen Handelns erklären und den Primat der Religion über alle anderen Felder individuellen und gesellschaftlichen Lebens behaupten, stehen für ein Postulat, ja eine Ideologie. Sie beschreiben nicht Geschichte im Sinne vergangener Realität. Das nordafrikanische Tunis in der ersten Hälfte des 19. Jahrhunderts, dem sich Lucette Valensi in ihrem Vortrag zuwendet, ist ein Beispiel. Als engagierte Vertreterin einer historischen Anthropologie, die über die Bedingungen von Konvivenz, 
Konflikt und interkulturellem Austausch generell gearbeitet und mit zahlreichen Monographien und Aufsätzen wesentlich zu den einschlägigen Diskussionen beigetragen hat, stellt sie die Frage nach dem Gewicht des religiösen Faktors in konkreten Feldern gesellschaftlichen Handelns und gesellschaftlicher Ordnung. Was für das Erziehungswesen gilt, so unterstreicht sie, gilt nicht unbedingt für Ökonomie und Diplomatie, und wie lokale Akteure ihr Verhältnis zu europäischen Christen oder zum christlichen Europa definierten, war in hohem Maße kontingent.

Noch weiter geht Leila Fawaz, prominente Sozialhistorikerin des heutigen Libanon und Syrien, deren Arbeiten den Rang von Standardwerken erlangt haben, die, mit anderem zeitlichen und geographischen Schwerpunkt, dezidiert gegen die hohe Gewichtung religiöser Faktoren im nahöstlichen Konfliktgeschehen des 19. und frühen 20. Jahrhunderts argumentiert. Religion ist auch für sie ein Faktor, dessen Bedeutung in konkreten Einzelfällen zu definieren bleibt, aber keineswegs ein dominanter. Auch dies widerspricht gängigen Wahrnehmungen, die unter heutigen arabischen Nationalisten und Islamisten ebenso verbreitet sind wie unter westlichen Beobachtern. Inwieweit erhöhte Mobilität im Kontext von Unruhen, Kriegen und Bürgerkriegen eine Verstärkung ethnisch-religiöser Loyalitäten und Identifikationen mit sich brachte, bliebe zu klären - eine der vielen Forschungsachsen, die sich nicht nur mit Blick auf den modernen Vorderen Orient abzeichnen.

Martin Tamcke, der mit seinen weitgespannten Forschungsinteressen, die die protestantische Theologie ebenso umfassen wie die Ost- und die orientalische Kirchengeschichte, gerade auf dem Feld der Missionsgeschichte mit wichtigen Beiträgen hervorgetreten ist, setzt andere Akzente: In seinem Vortrag geht es unmittelbar um Religion - zugespitzt auf das Phänomen der (protestantischen) deutschen Mission im Iran im 19. Jahrhundert - und Konflikt, genauer Kulturkonflikt. Die christliche Mission unter Christen, Juden und Muslimen - und die Reihenfolge ist nicht willkürlich - wird weithin unter dem Vorzeichen des Konflikts gesehen und erst allmählich als integraler Teil der Geistes- und Sozialgeschichte des Vorderen Orients wahrgenommen, namentlich der vielschichtigen Bemühungen um eine Reform von Individuum, Staat und Gesellschaft. Tamcke illustriert dies am konkreten Fallbeispiel. Zugleich beleuchtet er ein Moment, das auch bei Valensi und Fawaz aufscheint: Dass die Differenzen, Spannungen und Konflikte, soweit sie denn beobachtet und handlungsbestimmend werden, nicht notwendigerweise zwischen den Großgruppen der Muslime, Christen und Juden auftreten, sondern sehr häufig innerhalb dieser Großgruppen.

Differenzierung, jeder Wissenschaftler sollte es wissen, tut immer Not. Die Beiträge dieser Sektion unterstreichen dies nachdrücklich. 